\title{
The environment as an object of criminal law protection: problems of definition and legislative regulation
}

\author{
Olga Yakovleva* \\ Volgograd State University, 400062 Volgograd, Russian Federation
}

\begin{abstract}
The article is devoted to the study of the problems of definition and legislative regulation of the environment as an object of criminal law protection. The correct legislative regulation and the definition of the object and subject of the crime in the criminal law standard contribute to the correct labeling process. In the legal literature, there is no consensus on the definition of the object of environmental crimes. Some believe that the object of this group of crimes is the order of use of natural resources or social relations related to their economic exploitation; others believe that the relations of state ownership, which are expressed in natural resources; finally, the object of this group of crimes is directly the natural resources themselves or the entire environment. Taking into account the legislative regulation of norms united by generic and species groups and the scientific and theoretical definition of the direct object of the crime, we believe that the object of environmental crimes is public relations for the protection of the environment, the preservation of favorable natural conditions for nature, living beings and ensuring a sufficient level of environmental safety. In this context, a favorable environment should be considered as an environment whose quality ensures the safety of the natural environment functioning and other objects. The subject of crime in the science of criminal law makes it possible to solve many important issues from a practical point of view since it is characterized by relative criminal-legal independence: to distinguish between general and special elements of crimes; the subject of the crime allows you to reveal the nature and extent of the damage that was caused by the crime, as well as to identify the relationship between the criminal act and the consequences that occurred.
\end{abstract}

\section{Introduction}

The Constitution of the Russian Federation stipulates that a person, as well as his rights and freedoms, is of the highest value. In turn, the state is obliged to ensure the protection and observance of human and civil rights and freedoms. The Criminal Code of the Russian Federation reflects these provisions of the basic law of the Russian Federation by defining dangerous acts that are crimes that harm the individual, the entire society and the State as a whole. In Part 1 of Article 2 of the Criminal Code of the Russian Federation, the main tasks

\footnotetext{
* Corresponding author: repin80@mail.ru
} 
of this normative legal act are revealed, and this list indicates that not only the rights and freedoms of an individual and a citizen, property, public safety, and order, the constitutional system of the Russian Federation, as well as the environment should be protected [1].

Chapter 26 of the Criminal Code of the Russian Federation is devoted to environmental crimes. The acts covered by these elements encroach on the environment, which is the object of criminal law protection. It follows from the norms of the law that a favorable environment is an environment, the quality of which affects the successful natural functioning of natural ecological systems, as well as various natural objects. As can be seen from this formulation, the favorability of the environment is determined through the stability of the functioning of its components. A certain static state of the ecological environment is recognized as a value without taking into account the fact that any actions have negative or positive consequences. We come to the logical conclusion that the current legislation contains a formulation that is incorrect from the point of view of logic. In this case, in our opinion, the legislator should pay attention to the fact that: the environment can lose its favorable state due to both negative impacts (meaning pollution) and positive ones.

The contradiction that exists between the definition of an object, which is fixed in the current legislation, and the actual reality, can be resolved by replacing the stability criterion with the safety criterion [2].

The environment safe state is the main criterion when considering the conditions necessary for human habitation and survival, and also allows us to provide the factors that are developed in the environmental and legal literature. The presence of these factors (resource intensity, cleanliness, diversity, environmental sustainability, aesthetic richness) creates a favorable state of the environment [3].

The safety criterion will allow a positive assessment of the environment as favorable (in the presence of safe conditions) and unfavorable (in the absence of safe conditions). The favorable environment definition contained in the environmental legislation does not take into account the components of the natural environment as components of the environment. While natural ecological systems and natural objects act as a part and a whole, they are listed separately in the legislation.

\section{Materials and methods}

One of the problems in defining the environment as an object of criminal law protection is the inclusion of anthropogenic objects into the environment and their consolidation in the definition of "environment" [4, 5]. Researchers in various fields treat this problem differently. Thus, representatives of the first "camp" support the position on the inclusion of anthropogenic objects in the environment, referring to the successful experience of foreign colleagues [6]. Other scientists criticize this position, explaining that it will make the subject of legal regulation "limitless" [7]. It seems that it is not possible to imagine the environment without interaction and human influence on it. The environment, according to the interaction criterion with a person, consists of two parts: the human habitat is the one in which a person carries out his life activities and the environment that is not adapted for human life.

A comprehensive methodological approach to the study of this problem will allow us to determine the concepts of object and subject in acts that encroach on the natural environment (among the methods of cognition, the methods of system analysis and synthesis are of fundamental importance).

\section{Results and Discussion}


Today, at its core, the question of defining the concept of "object" in legal reality is not in doubt. Thus, the object of a crime is a public relationship protected by criminal law, which is directly encroached upon by a crime committed by a particular person. This composition element is the key to the labeling process. Since, thanks to it, it is possible to further determine the objective and subjective signs of the crime. In this regard, in our opinion, the correct legislative regulation and definition of the object and subject of the crime in the criminal law norm is mandatory. The subject of crime in the science of criminal law makes it possible to solve many important issues from a practical point of view since it is characterized by relative criminal-legal independence. First of all, to distinguish between general and special compositions, they are based on the subject of the crime. In addition, the subject of the crime allows you to reveal the nature and extent of the damage that was caused by the crime, as well as to identify the relationships between the criminal act and the consequences that occurred. When analyzing the criminal law standards of Chapter 26 of the Criminal Code of the Russian Federation, we found that often the regulation of the subject of environmental crimes is incorrect and requires adjustments. Referring to articles 246, 250, 251, 254 of the Criminal Code of the Russian Federation, we see that the subject of these acts is the rules of environmental protection, air, water, and soil.

From a criminal-legal point of view, rules cannot be the crime subject. The crime subject is characterized by materiality [8]. In turn, the rules are theoretical provisions on which the general order of something is based and at the same time act as a subject guide for certain actions [9]. Attention should also be drawn to the fact that the above approach confuses the definitions of the terms crime subject in the context of criminal law and the criminal encroachment subject in the understanding of criminalistics.

Let us turn to the scientific approaches to the term interpretation "crime subject". The researcher M. P. Bikmurzin believes that the crime subject can be information that was influenced by an external influence in the course of committing a crime [10]. In this approach, attention is drawn to the process of changing or destroying information that is contained in any material media. It is these actions that are criminally punishable from the point of view of the law. Adhering to this scientific position, the researchers point out that in some cases, namely, it applies to Articles 246, 250, 251, 254 of the Criminal Code of the Russian Federation, it does not confirm its effectiveness, because in this case there is an impact on other factors, but not on the rules. In this case, no harm is done to the rules. Based on the above, we conclude that the subject of a violation of the rules of environmental protection in the production of works is natural components (soil, air, water, atmospheric air, etc.). This point of view does not contradict the current legislation and theoretical provisions and concepts on ecology.

About Articles 250, 251, 254 of the Criminal Code, Article 246 of the Criminal Code is general, while the crime subject, which is provided for in Article 246 of the Criminal Code, are such natural components as: water, air, soil, from which it follows that the subject of criminal water pollution (Article 250 of the Criminal Code) is water; the subject of criminal air pollution (Article 251 of the Criminal Code) is atmospheric air, and the subject of land damage (Article 254 of the Criminal Code) is a land.

As the analysis shows, Article 250 of the Criminal Code of the Russian Federation identifies the concepts of a water source as a resource and waters as communication routes that perform the functional purpose of water transport. According to the researchers, in this norm of the Criminal Code of the Russian Federation, the legislator refers to underground, surface water, including also sources of road communication that are not intended for water storage (for example, tanks, etc.) [11].

Another important issue from a practical point of view is the inclusion of the following types of water bodies in the crime subject is a pond, a lake, including water bodies that are formed as a result of the negative impact of human factors on the environment. For example, 
it should be called "breathing lakes", which are unique phenomena that can arise and disappear in the depression of the terrain. It is not possible to call such objects full-fledged due to the lack of a complex set of features of a water body. Such facilities should be considered and attention should be paid to the problems of their development of measures to prevent the impact of harmful factors.

Legislators distinguish several types of water, including surface water, underground water, as well as sources of drinking water supply [12]. The Water Code of the Russian Federation discloses these types in detail. Thus, seas, straits, bays, reservoirs, swamps, glaciers, and others should be classified as surface waters. Underground waters include underground water basins and aquifers. As for the source of drinking water supply, it is necessary to characterize its specificity, which consists in the fact that such a source consists of both surface and underground water. For these types of water, it is possible to apply a single definition of water in the meaning of the chemical compound of oxygen and hydrogen in the solid, liquid, and gaseous states [13].

Based on the above, we can reveal the concept of "the subject of criminal water pollution", which includes water in the sense of a source of drinking water supply, which is endowed with a group of features characteristic of it as a chemical element. On the one hand, water, being a part of the natural environment, has a complex of features due to different geographical and natural conditions. On the other hand, from a social and economic point of view, water is important. Being an indispensable source of water supply. Based on these characteristics, we can distinguish the subject of environmental crimes from other crimes, in particular, crimes against property.

Article 252 of the Criminal Code of the Russian Federation defines the marine environment, which includes the internal seas of the Russian Federation, the territorial sea, and the open sea. The marine environment is a part of the environment that is restricted by the components of the world's oceans [13].

The most controversial and debatable in science and law enforcement practice is the determining question of the crime subject under Article 251 of the Criminal Code of the Russian Federation. According to the federal legislation that regulates relations in the field of atmospheric air protection, the natural component in question has high humidity and is considered as a mixture of atmospheric gases outside of residential and other premises. The criterion for determining the upper limit of atmospheric air is considered to be the average height of cloud cover propagation [14]. For violation of this border, criminal liability is provided. We believe that the concept of atmospheric air as a mixture of atmospheric gases located outside of residential or other premises should be used by the law enforcement officer when determining the subject of atmospheric air pollution. It should be noted that in case of labor protection violation, Article 143 of the Criminal Code of the Russian Federation provides for air pollution liability in industrial premises.

Analyzing various sources, we conclude that the concept of land can have a large number of meanings and be used in a broad and narrow sense.

Consider the concept definition of "land" used in the Criminal Code of the Russian Federation (Article 254). The explanatory dictionary of the Russian language gives the following interpretations of the concept under study: the third planet from the Sun; land; soil; the upper layer of the planet's crust, surface; loose, dark-brown matter that is part of the planet's crust; country, state; territory with land [9].

According to another definition, the earth is a part of the natural environment, the importance of which is difficult to overestimate, which has a group of characteristics: space, topography, climate, soil cover, etc. The land is home to various organizations and institutions that use the land as a production space. Moreover, for the production sphere, the land plays a primary role [15]. 
Researcher A. M. Anokhin, considering the concept of land as the subject of a crime, notes that this term can perform various functions: environmental, economic, etc. In this case, the ecological function is understood primarily as the connection of living and inanimate nature, and in the economic sense, the land acts as a means of production [16].

According to the fair remark of M. A. Article 254 of the Criminal Code of the Russian Federation provides for the following: regardless of the purpose and type of use of the land, it can also be the subject of a crime [14].

Thus, we conclude that the concept of "land" also refers to various land plots that represent a part of the earth's surface. We believe that when analyzing Article 254 of the Criminal Code of the Russian Federation, the conceptual meaning of "land" should be defined as follows: part of the surface of the earth (while not taking into account its functional purpose). With this approach, a part of the earth's surface also includes the soil layer, which means that in this case, the law enforcement officer will not be able to identify the land as the subject of environmental crimes and the land as the subject of crimes against property.

\section{Conclusions}

Taking into account the legislative regulation of norms united by generic and specific groups and the scientific and theoretical definition of the direct object of the crime, we believe that the object of environmental crimes should be understood as social relations that arise in the protection of the environment, the preservation of favorable natural conditions for nature and living beings, and in ensuring the environmental safety of people. In this context, a favorable environment should be considered as an environment whose quality ensures the safety of the natural environment functioning and other objects (natural, anthropogenic, etc.).

The provisions that we have proposed in this study regarding the subject of environmental crimes under Articles 246, 250, 251, 252, 254 of the Criminal Code of the Russian Federation allow us to perform the following important functions:

- To determine the material nature of the subject of the crimes under consideration, which becomes possible due to the study of the correspondence of the characteristics of the subject of environmental crimes to the general theoretical principles of criminal law science.

- Distinguish between general and special environmental crimes.

- Determine the causal relationship between criminal acts and the harmful consequences that have occurred. The external features of the object are determined by the form of criminal consequences (the severity of the damage caused) [17].

Thus, it is necessary to emphasize the special importance of considering the subject of infringement in the context of its connection with the object of an environmental crime. If this thesis is not followed, the crime qualification may be determined incorrectly [18].

\section{References}

1. V.V. Maltsev, Teaching about the object of the crime, 1 (Volgograd, 2010)

2. O. A. Yakovleva, Ubiquitous Computing and the Internet of Things: Prerequisites for the Development of ICT (Springer. Link, 2019)

3. A.V. Naumov, Application of the Criminal Code of the Russian Federation: Commentary on Judicial Practice and Doctrinal Interpretation (Moscow, 2005)

4. V. Y. Reshetnikov, IV International Scientific and Practical Conference "Legal Institutions and Methods of Environmental Protection in Russia, the CIS and the European Union: State and Efficiency", 4 (2017) 
5. O. A. Yakovleva, European Proceedings of Social and Behavioural Sciences, 104, 2357 (2020)

6. E. N. Abanina, O. V. Zenyukova, E. A. Sukhova, Commentary on Federal Law of 10.01. 2002 No. 7-FZ "On environmental protection" (Moscow, 2007)

7. M. M. Brinchuk, Journal of Russian Law, 9, (2008)

8. L. L. Kruglikov, Criminal law. General part (Moscow, 2005)

9. F.P. Filin, Explanatory Dictionary of the Russian Language (Moscow, 1981)

10. M. P. Bikmurzin, Subject of crime: theoretical and legal analysis (Saratov, 2005)

11. A. E. Zhalinsky, Commentary on the Criminal Code of the Russian Federation (Moscow, 2005)

12. E. Y. Gaevskaya, V. V. Kruglov, Environmental Law, 5, (2011)

13. Dictionary of the Russian language (Moscow, 1964)

14. M. A. Lapina, Legal Liability for Environmental Offenses (Moscow, 2003)

15. GOST 26640-85 "Earth. Terms and definitions "URL: http://www.gostrf.com/normadata/1/4294827/4294827799.pdf

16. A. M. Anokhin, Bulletin of Environmental Education in Russia, 3 (33) (2004)

17. O. A. Yakovleva, Bulletin of the Volgograd State University, 8 (2006)

18. P. U. Ismailova, Combating Atmospheric Pollution (Moscow, 2009) 